\title{
Analysis of landscape microclimate and green space transformation strategy for old residential areas—-case: Luoliu community
}

\author{
Aiping Gou', Yihan $\mathrm{Li}^{2}$, and Jiangbo Wang ${ }^{3, *}$ \\ ${ }^{1,2}$ Landscape Architecture Department, Ecology School, Shanghai Institute of Technology, Shanghai201418, China \\ ${ }^{3}$ Department of Architecture, Nanjiang Tech University, Nanjing, Jiangsu 211816, China
}

\begin{abstract}
As an old community, Luoliu community is representative in Shanghai. Traditional infrastructure is not combined with public space and green space layout, which makes the climate resilience of the old residential area urgently need to be improved. Through questionnaire survey, field measurement, combined with Envi-met to simulate microclimate changes and formulated green space resilience transformation strategies. Microclimate factors such as temperature, humidity, wind speed and wind direction change with the spatial distribution and vegetation structure. First, the walls of buildings are most vulnerable to the shadow of buildings. The microclimate of the building enclosed green space is stable, but its toughness is poor. Parallel green space can restrain the temperature rise to a certain extent, it has strong space toughness. Green enclosure space is also closed, usually covered with green plants. Although it can reduce the impact of solar radiation, overgrown and untrimmed trees will become an obstacle to air ducts. Ventilation should be the priority. Second, the canopy and vertical structure of green plants should be reasonable. Third, the combination layout of the dominant wind direction and the residential complex shall be considered comprehensively to plan the public facilities and sidewalks.
\end{abstract}

\section{Introduction}

The residential area is one of the spaces inextricably linked with urban residents ${ }^{[1]}$. Its microclimate bears a direct correlation to the comfort of residents ${ }^{[2][3]}$. The spatial arrangement of residential areas has an impact on its microclimate ${ }^{[4]}$. The old residential area stated in this paper is representative in Shanghai and even in China as a whole. The community thus described was completed long ago, weighing heavily against the updating of outdoor public space, the environment and the quality of residents' living, making the climate resilience a burning question.

\section{Research methods and data access}

\subsection{Research methods and subjects}

Luoliu Community consists of four parts (Luochuan, Luoping, Liuyi and Liuer) and a public path (“319”). Most of the buildings date from the 1950s to the 1980s. The plot ratio falls in the range of $1.0 \sim 1.9$, and the greening rate of the residential area $20 \% \sim 26 \%$. The majority of public space between houses have given way to the parking space.

According to the layout of community space, the green space fall into three categories: parallel, building

*Corresponding author: wjb@163.com enclosure and green enclosure. Measurements were carried out at nine points in Luoliu Community for information on green space needed for microclimate simulation in the residential area by means of ENVI-met, including the surrounding building (floor height, height, length, width), green space (length, width), spatial type (public green space, special green space, green space between houses, green space of road), plane layout (parallel type, building enclosure, green enclosure), plantation (arbor-shrub-grass mixture, arbor-grass combination, shrub-grass combination, arbor \& concrete). The parallel green space was confirmed at the points (1, $3,4,5,7)$, the green space of building enclosure at the points $(6,9)$, and the green space of enclosure at the points $(2,8)$ (Fig. 2).

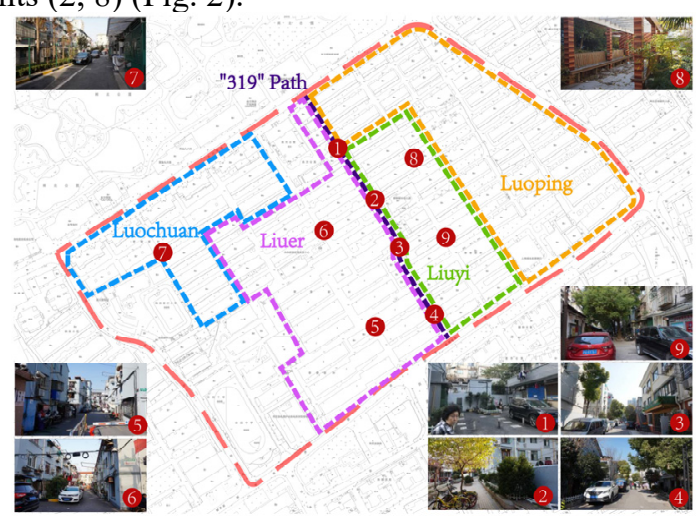

Fig. 19 Green Space in LuoLiu Community 


\subsection{Microclimate measurement and analysis based on ENVI -met}

Air temperature, relative humidity, air quality, air pollutants, wind direction and speed, surface temperature and wall temperature are measured at 9 points every two hours(Tab. 1). The measuring points extend to a vertical height of $1.5 \mathrm{~m}$. The measurements were conducted from 7:00 a.m, September 4, 2018 to 1:00 p.m. the following day every two hours. To reduce the error caused by the initial instrumentation, the measuring time was extended. In the final data simulation and statistical analysis, the relatively stable 24 -hour data were selected.

Tab. 1 Items of Data Measurements and Instruments

\begin{tabular}{ccc}
\hline Measuring items & Indicators & Instruments \\
\hline Temperature & Temperature & \\
humidity & $\begin{array}{c}\text { Relative } \\
\text { humidity }\end{array}$ & $\begin{array}{c}\text { Bolangtong } \\
\text { hand-held air } \\
\text { detector }\end{array}$ \\
Air quality & $\begin{array}{c}\text { HCHO, PM1.0, } \\
\text { PM2.5, PM10 }\end{array}$ & \\
& & NK portable \\
Wind speed and & Wind speed and & anemometer \\
wind direction & wind direction & (USA) \\
& & Dongmei \\
Surface and wall & Surface and wall \\
temperatures & temperatures & infrared thermal \\
& & imager \\
& Building height, & Dongmei \\
information & telescope \\
& green space size & rangefinder \\
& &
\end{tabular}

Based on the root-mean-square error (RMSE) and mean absolute percentage error (MAPE), the effectiveness of simulation results is evaluated.

$$
\begin{aligned}
\text { RMSE } & =\sqrt{1 / n \sum_{i=1}^{n}\left(y_{i}^{r}-y_{i}\right)^{2}} \\
\text { MAPE }= & \frac{1}{n \sum_{i=1}^{n} \frac{\left|y_{i}^{r}-y_{i}\right|}{y_{i}^{r}}} \times 100 \%
\end{aligned}
$$

The average absolute percentage error between air temperature, relative humidity and measured value ranges between $2 \%-18 \%$. The results show that the error range of the model simulation results fall in the range of $1.31{ }^{\circ} \mathrm{C}-1.63^{\circ} \mathrm{C}$, and the MAPE of relative humidity is less than $5 \%$. It can be concluded that the error between the measured value and the simulation value is kept within reasonable bounds ${ }^{[5]}$.

\subsection{Survey of thermal comfort}

There were 180 subjects in the study from 9 points. , including 73 males (40.6\%) and 107 females (59.4\%), as shown in Fig. 2. In terms of gender, women are slightly more than men. There are 59 residents over 60, accounting for $32.8 \%$ of the total, a major reflection on the age distribution of the Community (Fig. 3). The aging trend of the community is evident, and the retirees make up a large proportion of the respondents.

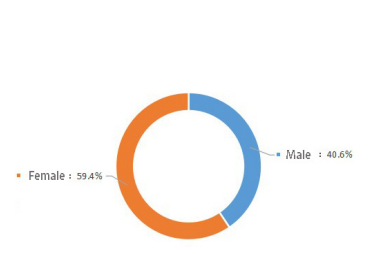

Fig.2 Gender ratio

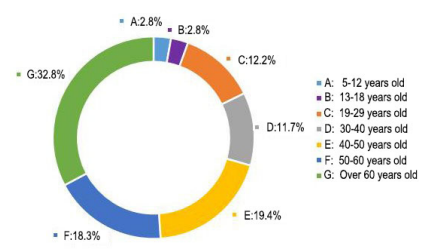

Fig.3 Age ratio

\section{Result Analysis}

\subsection{Microclimate data measurements}

The effects of green space on temperature vary according to the layout and structure ${ }^{[6]}$. The initial temperature of building enclosure is slightly higher than that at other points, and the air temperature on site is prone to drastic fluctuations arising from the tree crown and building shadow; the parallel and green enclosure can hold down the rise of air temperature. The ambient temperature is greatly affected by the plants.

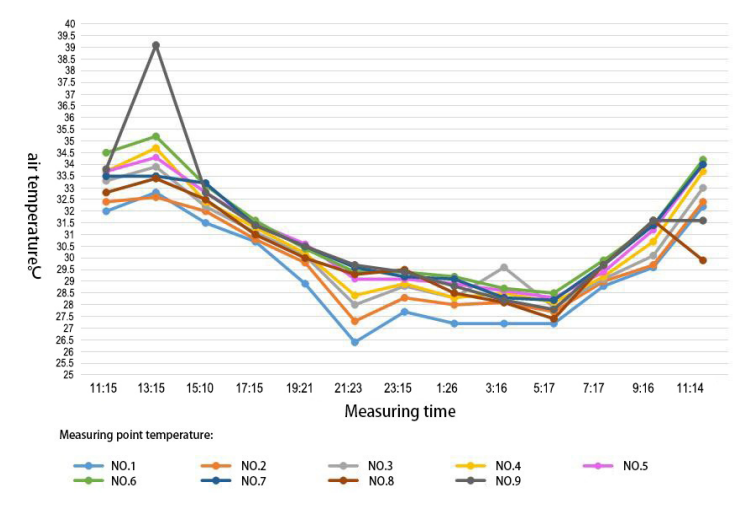

Figure.4 Air temperature

Due to the ecological effect of plant cooling and humidification, the relative humidity of green enclosure is the highest of all the three forms at the peak of humidity, such as 11:15 a.m., 15:10 p.m. on September 4 and 5:17 a.m. on the following day, and the natural "Canyon wind" is easy to blow up in the parallel green space because of the buildings on both sides, making stable the wind environment and relative humidity. It is arguably the best of the three spatial layouts. The building enclosure is liable to whirlwind because the environment is enclosed and has its limitations. In times of good ventilation, the humidity on site increases; when the wind is unavailable, the temperature decreases correspondingly. 


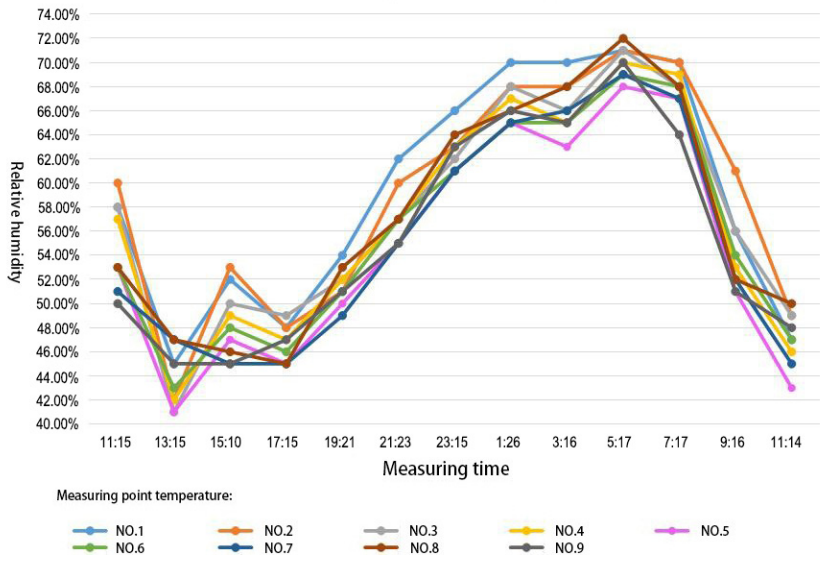

Figure.5 Relative humidity

By comparing PM2.5 and PM10 at nine points, there are three peak periods of air quality in 24 hours: 11:15 a.m. and 15:10 p.m. on September 4 and 7:17 a.m. on the following day, respectively(Tab. 2). 7:17 is supreme and unchallenged of the three peaks. At this time, PM2.5 at
Point 1 (parallel green space) and Point 6 (building enclosure) is the highest of all the nine points, and PM10 at Point 6 is the highest. According to the statistics of the mean value, the result of green enclosure and building enclosure is higher than that of the parallel type.

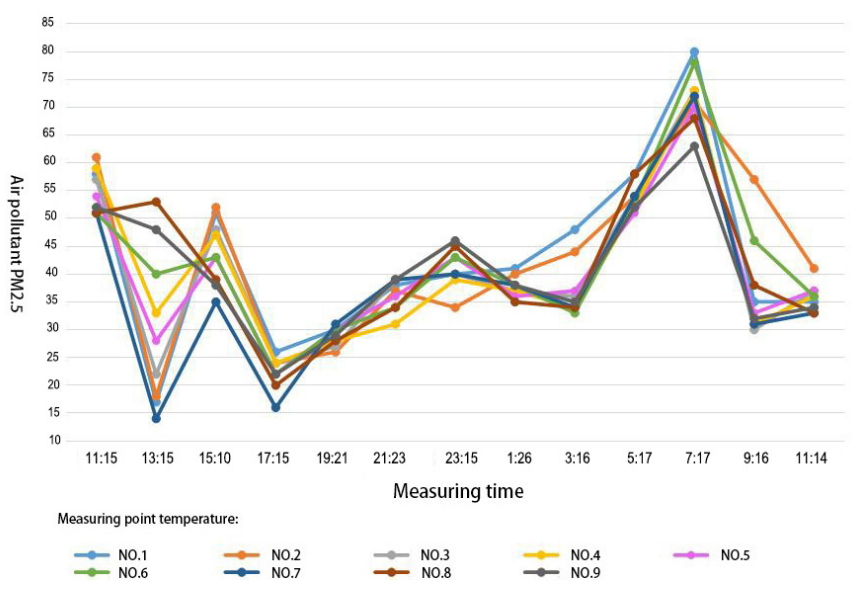

Figure.6 PM2.5

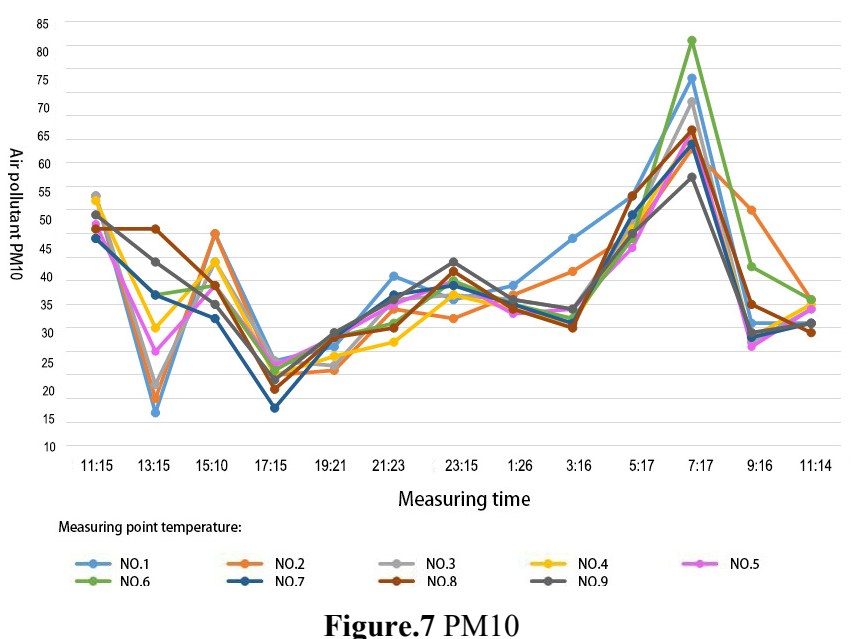

\subsection{Survey results of thermal comfort}

According to the OSV survey (comprehensive comfort), 93 people at nine points felt somewhat uncomfortable, accounting for $52 \%$ of the total. On the whole, the discomfort at Point 3 (parallel), Point 4 (parallel) and Point 6 (building enclosure) is more noticeable than that at other points, while the feeling at Point 8 (green enclosure) is more pleasant (Fig. 8). 


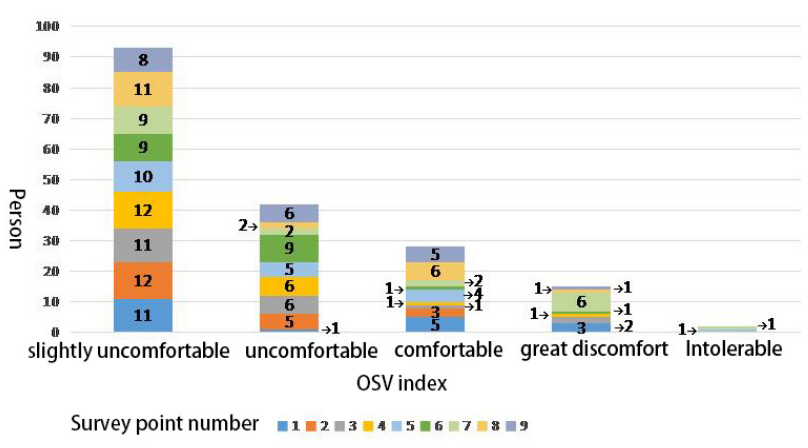

Fig. 8 OSV survey results

\subsection{Transformation strategy}

The addition of corridor frame (such as Point 1 and 4) in the parallel green space can mitigate the radiation of sunshine on the ground and walls, and reduce the ambient temperature; the water body at (Point 7, for instance) can make the site humid and lead the air passage into the site; the horizontal division of the road at (Point 5, for instance) can form the air passage for cooling and humidification.

If the water body is set in the center or plants are combined with the water body during the design and transformation of building enclosure, the site will be cooled and humidified. Opening the air outlet and reducing the shelter of large trees can lead the wind into the site, promote the moisture cycle of the green space and the external space, thus making the place more comfortable.

Considering the effect of greening on the cooling and humidification of green enclosure, firstly, it is necessary to maintain a certain coverage of greening; and secondly, at the air inlet, reduce the number of trees at the vent, open the air vent, increase the exchange of media to make the place more comfortable.

\section{Conclusion}

First, ventilation should be the priority. Second, the canopy and vertical structure of green plants should be reasonable. Third, the combination layout of the dominant wind direction and the residential complex shall be considered comprehensively to plan the public facilities and sidewalks.

\section{Discussion}

For one reason or another, this study has the following shortcomings:

With regard to green structure, landscape methods such as stone placement, sketch, landscape wall and benches, are not considered, except the characteristics of green space like scale, area and green coverage; and other landscape methods have an impact on microclimate.

Although the envi-met software can be used to select the variety of plants, the specific dimensions of tree branches and crown lengths cannot be displayed in the model, which causes inaccurate interaction simulation of tree trunk, crown, leaf surface and atmospheric environment in the microclimate.

\section{References}

1. L. Liu, J. Li, Sci. Technol. Info. J. 29, 129 (2009).

2. G. Du, Numerical Simulation of Wind Environment in Typical Layout Residential Areas (2009).

3. G.Yuan, Research on the Wind Effect of Tianjin High-Rise Residential Areas with the Plane Layout (2012).

4. L. Quan, B. Ning, Chinese. Hortic. Abstr. J. 33, 60-65 (2017).

5. E. Lahme, M. Bruse, ICUC5, Lodz, 1-5 (2003).

6. M. F. Shahidan, P. J. Jones, J. Gwilliam, E. Salleh, Build. Environ. J. 58, 245-257 (2012). 